\title{
NÍVEL DE TRANSPARÊNCIA DOS MUNICÍPIOS DO ESTADO DE SANTA CATARINA SOB A ÓTICA DA LEI 12.527/2011 E EFICIÊNCIA NA UTILIZAÇÃO DAS RECEITAS ${ }^{1}$
}

\section{LEVEL OF TRANSPARENCY OF MUNICIPALITIES OF SANTA CATARINA STATE UNDER THE PERSPECTIVE OF LAW 12.527/2011 USE EFFICIENCY AND REVENUE}

\section{NIVEL DE TRANSPARENCIA DE LOS MUNICIPIOS DE SANTA CATARINA DEL ESTADO BAJO LA PERSPECTIVA DE LA LEY 12.527/2011 EFICIENCIA DEL USO E INGRESOS}

Marcio Roberto Piccoli, Mestrando em Ciências Contábeis pela Universidade Regional de Blumenau - FURB. Endereço Profissional: Rua Getúlio Vargas, 2125, Bairro Flor da Serra Área das Ciências Sociais Aplicadas - ACSA, CEP: 89600-000, Joaçaba - SC - Brasil.

Telefone: 493551 2081, E-mail: marcio.piccoli@unoesc.edu.br.

Geovanne Dias de Moura, Doutor em Ciências Contábeis e Administração pela Universidade Regional de Blumenau - FURB. Endereço Profissional: Rua Antonio da Veiga, 140, Sala D-202, Campus I, Victor Konder, CEP 89012-900, Blumenau, SC - Brasil.

Telefone: 473321 0938, E-mail: geomoura@ terra.com.br.

Carlos Eduardo Facin Lavarda, Doutor em Contabilidade pela Universitat de Valencia, Espanha. Endereço Profissional: Universidade Regional de Blumenau. Endereço Profissional:

Rua Antonio da Veiga, 140, Sala D-202, Campus I, Victor Konder, CEP 89012-900, Blumenau, SC - Brasil. Telefone: 473321 0938. URL da Homepage: www.furb.br/ppgcc, Email: clavarda@furb.br/ elavarda@gmail.com.

\begin{abstract}
RESUMO
A pesquisa objetivou analisar o nível de transparência dos municípios do Estado de Santa Catarina sob a ótica da Lei 12.527/2011 e sua correlação com a eficiência na utilização das receitas. Para tal, realizou-se pesquisa descritiva, conduzida por meio de análise documental e abordagem quantitativa. A amostra, intencional e não probabilística, compreendeu 61 municípios catarinenses, tendo os dados coletados de outubro a dezembro de 2013. Na análise dos dados utilizaram-se medidas de estatísticas descritivas, entropia informacional, cálculo da eficiência com o software MaxDEA e análise de correlação de Pearson. Os resultados revelaram um nível médio de evidenciação de apenas 46,65\%, muito distante de $100 \%$. Alguns municípios não divulgaram nenhuma das informações e nenhum deles atingiu $100 \%$ de informações evidenciadas. Os cálculos obtidos por meio do DEA demonstraram que 22 munícipios, dos 61 analisados, atingiram score 1, ou seja, apenas a minoria pode ser considerada eficiente na utilização dos recursos públicos. Por fim, constatou-se que a variável evidenciação obrigatória tem correlação positiva de $16 \%$ com a variável eficiência na utilização das receitas públicas do ano de 2012, no entanto, não é estatisticamente significativa, podendo-se inferir que os resultados sinalizam que a combinação entre receitas
\end{abstract}

\footnotetext{
${ }^{1}$ Artigo submetido em 11/07/2014, revisado em 11/08/2014, aceito em 13/08/2014 e divulgado em 01/12/2014 pelo Editor João Carlos Hipólito Bernardes do Nascimento, após double blind review.
}

GєCont, v. 1, n. 2, Floriano-PI, Jan-Jun. 2014. 
públicas utilizadas e os indicadores socioeconômico e tamanho não são variáveis que contribuem para aumentar o nível de evidenciação obrigatória.

Palavras-chave: Nível de transparência. Municípios catarinenses. Eficiência na utilização das receitas.

\begin{abstract}
The research aimed to analyse the level of transparency of the municipalities of the State of Santa Catarina from the perspective of the Brazilian Law 12.527/2011 and it's the correlation with the efficient use of revenues. To that this end, we performed descriptive research conducted through document analysis and quantitative approach. The sample, intentional and non-probabilistic understood 61 municipalities of Santa Catarina and the data collected from October to December 2013. In the data analysis we used measures of descriptive statistics, informational entropy, calculating the efficiency with MaxDEA software and Pearson correlation analysis. The results revealed an average, far from 100\% level of disclosure of only 46.65\%. Some municipalities have disclosed no information and none of them reached $100 \%$ of information evidenced. The calculations obtained by the DEA showed that 22 municipalities, of 61 analyzed, reached score 1, ie what means, only a minority can be considered an efficient use of public resources. Finally, it was found that the mandatory disclosure variable has a positive correlation of $16 \%$ with variable efficiency in the use of public revenues in the year 2012, however, is not statistically significant, it can be inferred that the results indicate that the combination between government revenue and used the size and socioeconomic indicators are not variables that contribute to increase the level of mandatory disclosure.
\end{abstract}

Keywords: Level of transparency. Municipalities of Santa Catarina. Efficient use of revenues.

\title{
RESUMEN
}

La investigación tuvo como objetivo analizar el nivel de transparencia de los municipios del Estado de Santa Catarina, desde la perspectiva de la Ley Brasilena 12.527/2011 y su correlación con el uso eficiente de los ingresos. Para ello, se realizó una investigación descriptiva realizada a través del análisis de documentos y enfoque cuantitativo. La muestra, intencional y no probabilística entendían 61 municipios de Santa Catarina y los datos recogidos entre octubre y diciembre de 2013. El análisis de los datos se utilizaron medidas de estadística descriptiva, la entropía de información, el cálculo de la eficiencia con software MaxDEA y el análisis de correlación de Pearson. Los resultados revelaron un promedio, lejos de nivel del 100\% de la divulgación de sólo 46,65\%. Algunos municipios han revelado la existencia de información y ninguna de ellas alcanzó el 100 \% de la información pone de manifiesto. Los cálculos obtenidos por la DEA demostraron que 22 municipios, de los 61 analizados, alcanzaron puntuación de 1 , es decir, sólo una minoría puede considerarse un uso eficiente de los recursos públicos. Por último, se encontró que la variable de divulgación obligatoria tiene una correlación positiva del $16 \%$ con una eficiencia variable en el uso de los ingresos públicos en el año 2012, sin embargo, no es estadísticamente significativa, se puede inferir que los resultados indican que la combinación entre los ingresos del gobierno y se utiliza el tamaño y los indicadores socioeconómicos no son variables que contribuyen a aumentar el nivel de divulgación obligatoria.

Palabras clave: nivel de transparencia. Municipios de Santa Catarina. El uso eficiente de los ingresos.

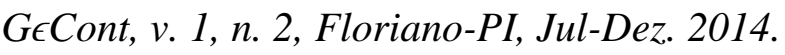




\section{INTRODUÇÃO}

7 odas as entidades públicas brasileiras tem a obrigatoriedade de divulgar suas ações a partir da Promulgação da Constituição Federal de 1988, mas foi com o advento da Lei Complementar 101/2001 denominada de Lei de Responsabilidade Fiscal (LRF) que essa exigência foi mais aplicada pelas entidades, sendo punidos os administradores que não cumprem com as determinações legais nela impostas.

A LRF tem como objetivo o planejamento, o controle e a transparência das contas públicas, a qual estabelece a toda população acima da publicidade, a garantia de cada cidadão acompanhar os gastos públicos, constituindo, assim, uma política de gestão responsável e favorecendo dessa forma a cidadania de cada cidadão (NETO et al., 2006).

Nessa evolução de transparência das contas públicas, foi aprovada a Lei Complementar (LC) 131/2009 de 27 de maio de 2009, que diz respeito à mudança de procedimentos contábeis ensejando uma melhora na evidenciação e transparência dos atos e fatos da administração pública, a qual estabeleceu um cronograma para que todos os municípios da Federação se adequassem as suas exigências, realizando de forma transparente a divulgação das contas, ou seja, a execução orçamentária, envolvendo dessa forma as receitas e despesas, tendo como prazo máximo para os municípios se adequarem, maio de 2013.

Por fim, em novembro de 2011 foi sancionada a Lei 12.527/2011, mais conhecida como Lei de Acesso a Informação, a qual estabelece os procedimentos para que todos os entes públicos disponibilizem e facilitem o acesso de todos às informações consideradas públicas.

Para Viccari Junior et al. (2009), o poder público a fim de atingir seus objetivos de transparência e informação de seus custos aos cidadãos, devem informar de forma transparente suas ações, ou seja, apresentar informações que sejam acessíveis, compreensíveis e que possam ser úteis a população.

Como percebemos, o Brasil vem evoluindo em relação à transparência de seus atos, tendo como obrigatoriedade aos gestores facilitar o acesso às contas públicas a partir da implantação de portais de transparência, os quais de acordo com as leis citadas já são obrigatórios e precisam estar disponíveis para toda população, independente do número de habitantes.

Nesse contexto, onde há a obrigatoriedade de divulgação das informações públicas, a questão de pesquisa que orienta este estudo é: Municípios que possuem maior eficiência na utilização das receitas apresentam maiores níveis de transparência? Assim, o objetivo do estudo é analisar o nível de transparência dos municípios do Estado de Santa Catarina sob a ótica da Lei 12.527/2011 e sua correlação com a eficiência na utilização das receitas.

Com estudos recentes realizados sobre o tema, Keunecke, Teles e Flach (2011) investigaram, à luz da LC 131/2009, qual era o nível de transparência dos cinco maiores municípios mais populosos de Santa Catarina, concluindo que os municípios pesquisados cumprem com as determinações da referida Lei, porém, os autores ressalvam que o conteúdo disponível em relação a séries históricas e quantidade de relatórios sobre a execução físcal dá margem a interpretações no que se refere à divulgação de "informações pormenorizadas" sobre a "execução orçamentária e financeira", conforme disposto na referida Lei.

Raupp e Pinho (2012) buscaram identificar nos sites das Câmaras Municipais de Santa Catarina informações referentes ao cumprimento da transparência das contas públicas. Sendo investigados 95 sites de Câmaras Municipais, os autores concluíram que, em 2012, a divulgação ainda era incipiente, principalmente, nos municípios abaixo de 10 mil habitantes. 
Apresenta-se como lacuna para nosso estudo, a necessidade de verificação do cumprimento da Lei de Acesso a Informação, haja vista, que não existem estudos dessa natureza investigando os municípios de Santa Catarina, ao passo que a Lei 12.527/2011 é recente, mas em vigor desde janeiro de 2012. Por outro lado, não se encontrou estudos relacionando a transparência pública com a eficiência na aplicação das receitas.

\section{REFERENCIAL TEÓRICO}

Para dar suporte ao estudo, esta seção aborda a transparência a partir das legislações brasileiras, observando a Lei de Responsabilidade Fiscal (LRF/2000), LC 131/2009 e Lei 12.527/2011, bem como a transparência pública a partir de estudos sobre o tema já realizados.

\subsection{Transparência e a Legislação Brasileira}

O princípio da transparência pública está regulamentada no artigo 37 da CF de 1988 no qual o caput do artigo estabelece que a administração pública seja ela direta ou indireta de qualquer um dos poderes (União, Estados, Distrito Federal e Municípios) obedecerão aos princípios da legalidade, impessoalidade, moralidade, publicidade e eficiência. No que se refere à transparência, a Carta Magna dispõe em seu $\S 1^{\circ}$ o seguinte:

$\S 1^{\circ}$ - A publicidade dos atos, programas, obras, serviços e campanhas dos órgãos públicos deverá ter caráter educativo, informativo ou de orientação social, dela não podendo constar nomes, símbolos ou imagens que caracterizem promoção pessoal de autoridades ou servidores públicos.

A partir do ano de 2000, com a promulgação da $L C$ n $^{\circ} 101$ de 04 de maio do mesmo ano (LRF), a qual trouxe em seu bojo quatro pilares importantes para a gestão pública: planejamento governamental, equilíbrio fiscal, endividamento público e, por fim, a transparência, as ações das entidades públicas brasileiras passaram a ser mais expostas às cobranças da sociedade civil.

O princípio da transparência, para Cruz et al. (2000) é mais abrangente que a publicidade, ou seja, a divulgação dos atos públicos precisa ser divulgado e acima de tudo compreensível, caso contrário não se pode afirmar que existe transparência.

Nesse sentido, para Neto et al. (2007) a "transparência como princípio da gestão fiscal responsável, pressupõe a publicidade e a compreensibilidade das informações". Então, para que se tenha um melhor entendimento das informações públicas divulgadas, se faz necessário que a gestão seja eficiente e que os atos nela praticados sejam compreensíveis aos olhos da população.

A publicidade emanada no artigo 37 da CF, de acordo com Meirelles (2006) deve abranger toda a atuação do estado, ou seja, não somente no aspecto de divulgação de seus atos, mas, acima de tudo, proporcionar à sociedade conhecer a conduta interna de seus governantes.

No artigo 48 da LRF, consta que a gestão fiscal transparente passa pela divulgação dos planos orçamentários, ou seja, o plano plurianual, a lei de diretrizes orçamentárias e o orçamento, bem como as prestações de contas anuais e o respectivo parecer prévio emitido pelos Tribunais de Contas referentes aos gastos realizados pela entidade.

A fim de facilitar o entendimento do referido artigo da LRF, em 27 de maio de 2009, a LC 131/2009, concomitante com o Decreto n. 7.185 de 27 de maio de 2010, trouxeram, para 
que se tenha uma melhor transparência das contas públicas, a obrigatoriedade da divulgação em tempo real das informações pormenorizadas das receitas e despesas públicas, incentivando a participação popular em audiências públicas durante a elaboração dos planos de governo, isto é, a divulgação em tempo real entendida como aquela disponibilização de informações até o primeiro dia útil subsequente à data do registro contábil. Nesse sentido, a divulgação da eficiência na aplicação dos recursos públicos (receitas) precisa, acima de tudo, desempenhar um papel social de prestação de contas para a sociedade.

Considerando que a transparência pública é direito de cada cidadão, Bellver e Kahfmann (2005) asseveram que, em sociedades onde há democracia, o acesso à informação pode ser considerado como um direito humano. No Brasil, esse direito já está assegurado legalmente a todo cidadão pela CF de 1988.

A transparência, conforme menciona Cruz et al. (2012), deve ser um dos princípios da governança pública, visando sempre o aperfeiçoamento das ações governamentais consideradas como boas práticas de administração pública, considerando que todo cidadão tenha acesso e compreensão daquilo que os gestores realizam a partir do que lhes foi confiado.

A divulgação de informações, sejam elas contábeis, sociais ou administrativas, ajudam o cidadão a obter dos entes públicos informações sobre suas ações no que se refere aos projetos e programas por eles implementados, visando além de uma garantia de sustentabilidade econômica, como também a manutenção de um direito legítimo do cidadão (EVELINO; COLAUTO; ANGNOTTI, 2012). Dessa forma, entende-se que, para haver um efetivo acompanhamento dos recursos públicos, a destinação correta dos recursos deve ser um ponto fundamental das observações fiscais a serem realizadas pelos cidadãos.

Mantendo a evolução de um governo democrático e transparente, foi promulgado em novembro de 2011 a Lei $\mathrm{n}^{\mathrm{o}}$ 12.527/2011, atualmente denominada de Lei de Acesso a Informação, tendo como principal objetivo a garantia e aplicabilidade do direito fundamental do acesso à informação.

A referida Lei define que os procedimentos nela previstos, asseguram o direito fundamental de acesso a informação e devem ser realizados em conformidade com os princípios da administração pública seguindo as diretrizes contidas nos incisos I ao V:

\footnotetext{
Art. $3^{\circ}[\ldots]$

I - observância da publicidade como preceito geral e do sigilo como exceção;

II - divulgação de informações de interesse público, independentemente de solicitações;

III - utilização de meios de comunicação viabilizados pela tecnologia da informação;

IV - fomento ao desenvolvimento da cultura de transparência na administração pública;

V - desenvolvimento do controle social da administração pública.
}

Nesse ínterim, a Lei estabelece que a divulgação das informações deve ser disponibilizada em sítio próprio da entidade tendo como ferramenta a rede mundial de computadores. A Lei estabelece ainda que os municípios abaixo de 10 mil habitantes ficam dispensados do cumprimento desta Lei, ficando estes obrigados a divulgarem as informações financeiras e orçamentárias conforme prevê a LRF e a LC 131/2009.

A Lei de Acesso a Informação estabelece que cada ente da federação e suas entidades regulamentem de acordo com suas necessidades o atendimento aos dispositivos desta, a fim de promover o acesso à informação por parte de toda população. 
Para Plat Neto et al. (2007), a transparência das contas públicas pressupõe o fornecimento de informações confiáveis e relevantes aos interesses da população, sendo este um dos usuários das informações públicas. Para tal, o autor apresenta que os elementos da transparência das contas públicas devem ser pautados na publicidade: divulgação e acesso; compreensibilidade: linguagem e apresentação e utilidade das informações: relevância, comparabilidade e confiabilidade.

A transparência das contas públicas no Brasil é objeto de muitos estudos já realizados, a fim de demonstrar a evolução da gestão transparente cumprindo com os deveres emanados pelas respectivas leis já mencionadas. Passamos então a apresentar, alguns dos estudos sobre o tema já realizados.

\subsection{Transparência na Gestão Pública}

Um dos primeiros estudos sobre o tema realizados no Brasil foi o de Akutsu e Pinho (2002), os quais investigaram a transparência de informações públicas em portais do governo brasileiro a partir de uma análise de como a internet, um dos instrumentos básicos de informação tem sido utilizada por gestores públicos para incremento da accountability na construção de uma sociedade mais democrática.

A partir de critérios definidos pelos autores, a pesquisa foi baseada em 20 portais governamentais disponibilizados pelo poder Executivo, sendo eles: Governo Federal, Distrito Federal, Bahia, Ceara, Minas Gerais, Paraná, Pernambuco, Estado do Rio de Janeiro, Rio Grande do Sul, Santa Catarina, Estado de São Paulo, Salvador, Fortaleza, Belo Horizonte, Curitiba, Recife, Município do Rio de Janeiro, Porto Alegre, Florianópolis e Município de São Paulo.

Como principais resultados do estudo, os autores apontam, que na maioria dos casos, ha ausência de accountability, e a consequente manutenção do patrimonialismo e da democracia delegativa na sociedade brasileira. Não obstante, alguns resultados pontuais, porém significativos, evidenciam avanços por parte dos gestores em direção a uma maior accountability e, portanto, à construção de uma sociedade mais democrática, conforme previsto pelos teóricos da sociedade da informação.

Para Akutsu e Pinho (2002), accountability diz respeito a uma prestação de contas públicas confiável por parte dos governantes, sendo estas também auditadas pelos controles interno (própria da entidade) e externo (Tribunais de Contas). Neste mesmo pensamento, Campos (1990) já preceituava que accountability deve ser pensada como transparência, prestação de contas por parte dos governantes e a devida responsabilização destes pelos atos praticados. Quanto ao patrimonialismo identificado por Akutsu e Pinho (2002), segundo Amorim (2000), é a herança do regime militar vivido pelo país e a correlação de forças políticas brasileiras que, de certa forma, contribuem para a fraca transparência pública.

Lemos et al. (2004) investigaram as interfaces dos portais governamentais, a fim de identificar se os sites governamentais proporcionam uma interação com a sociedade proporcionando ao usuário um grau de acessibilidade, otimização, navegabilidade e possíveis tratamento de erros. A partir da análise dos portais de três capitais: Rio de Janeiro, São Paulo e Porto Alegre e mais o estado de São Paulo, os autores concluíram que há significativas deficiências nos portais analisados. Dos 23 critérios verificados em todas as categorias de análise, cada site individualmente só conseguiu aprovação em 12 deles sendo atendidos pelos dois portais de São Paulo e pelo do Estado do Rio de Janeiro. Porto Alegre apresentou a mais baixa performance, com aprovação em apenas seis critérios.

Prado (2004), a partir do estudo sobre transparência das contas públicas, investigou o governo eletrônico e a transparência: a publicização das contas públicas das capitais 
brasileiras. Em sua análise, o autor identificou que Os websites de Belo Horizonte, Curitiba, Florianópolis, Porto Alegre, Rio de Janeiro e São Paulo podem ser considerados os mais completos existentes, com grande oferta de informações e serviços e navegação mais amigável.

Os sites de Aracajú, Belém, Belo Horizonte, Boa Vista, Fortaleza, Goiânia, Maceió, Manaus, Porto Alegre, Rio de Janeiro, Salvador, São Luiz, São Paulo e Vitória não apresentam em suas páginas um direcionamento de acesso as suas contas públicas, representando 53,85\% das capitais brasileiras. Por outro lado, apenas Belém, Boa Vista e Cuiabá não apresentam qualquer site disponibilizando informações de suas contas públicas, as demais, 23 capitais apresentam parcial ou integral informações atualizadas em cumprimento a LRF.

Platt Neto et al. (2007) tiveram como tema de pesquisa, a Publicidade e Transparência das Contas Públicas: obrigatoriedade e abrangência desses princípios na administração pública brasileira, tendo como objetivo caracterizar a obrigatoriedade e abrangência dos princípios da publicidade e da transparência na administração pública brasileira, com enfoque na divulgação das contas públicas, a partir de uma abordagem exploratória bibliográfica visando formar uma base conceitual e legal para a abordagem do problema.

Os autores concluíram que a Internet constitui uma forma emergente para a divulgação das contas públicas, com maior destaque a partir da Lei de Responsabilidade Fiscal. Os autores ressaltam que mais do que garantir o atendimento das normas legais, as iniciativas de transparência na administração pública constituem uma política de gestão responsável que favorece o exercício da cidadania pela população, na qual a compreensibilidade dos dados e das informações pelos usuários é uma condição indispensável.

A transparência da gestão fiscal, a partir de um estudo dos portais eletrônicos dos maiores municípios do Estado do Rio de Janeiro, tendo como amostra 23 portais selecionados com a finalidade de mensurar o nível de transparência fiscal eletrônica utilizando parâmetros de correlação e de regressão, foi o tema da pesquisa de Cruz, Silva e Santos (2009).

As evidências encontradas pelos autores apontam, apesar de os municípios serem considerados de grande porte, baixos níveis de transparência fiscal eletrônica, considerados incompatíveis com seu desenvolvimento socioeconômico e ainda relações positivas e significativas entre nível de transparência fiscal eletrônica e as variáveis: população, receita orçamentária, taxa de alfabetização, IDH (índice de desenvolvimento humano), IQM (índice de qualidade dos municípios) e estágio do site (CRUZ; SILVA; SANTOS, 2009)

Keunecke, Teles e Flach (2011) pesquisaram as práticas de accountability nos municípios mais populosos de Santa Catarina, tendo como objetivo analisar o nível de transparência dos sítios eletrônicos dos cinco municípios catarinenses mais populosos, a fim de identificar se tais municípios estão atendendo satisfatoriamente as obrigações da Lei de Responsabilidade Fiscal.

Os resultados da pesquisa, a qual investigou os municípios de Joinville, Florianópolis Blumenau, São José e Criciúma, apontam que todos os municípios atendem a Lei Complementar $n^{\circ} 131$ de 2009 e reforça a importância de que as contas públicas sejam divulgadas de forma a facilitar a accountability e a sua compreensão por parte dos cidadãos, porém há de se atentar para o conteúdo disponível, em relação a séries históricas e quantidade de relatórios sobre a execução fiscal, dando margem a interpretações no que se refere à divulgação de "informações pormenorizadas sobre a "execução orçamentária e financeira", conforme disposto na referida Lei". A partir da metodologia adotada, os autores elaboraram 
um ranking dos municípios analisados, estando em primeiro lugar com alto nível de transparência o município de São José.

A utilização dos portais eletrônicos de câmaras municipais, como promotoras da prestação de contas, transparência e participação a partir da análise de 93 portais Legislativos do estado de Santa Catarina, foi o objeto de pesquisa de Raupp e Pinho (2012). Tendo como abordagem descritiva, os autores concluíram que o conjunto dos portais eletrônicos de câmaras municipais de Santa Catarina mostra ausência de capacidade de viabilizar a construção das dimensões da accountability.

Os portais configuram muito mais a existência de murais eletrônicos do que espaços de construção da accountability, respondendo a um requerimento, um impulso da modernidade expresso por um imperativo tecnológico dominante, porém, não contribuem para o desenvolvimento da transparência, prestação de contas e participação (RAUPP; PINHO, 2012).

\section{PROCEDIMENTOS METODOLÓGICOS}

Para atender ao objetivo proposto no artigo, realizou-se pesquisa descritiva, conduzida por meio de análise documental e abordagem quantitativa. A população do estudo engloba os 295 municípios do estado de Santa Catarina, conforme disponibilizado no site do IBGE (www.ibge.gov.br), referente ao ano de 2010. A amostra é considerada intencional e não probabilística, compreendendo os 61 municípios catarinenses que possuem mais de vinte mil habitantes.

Inicialmente, foi calculado o índice de conformidade das informações que deveriam ser divulgadas nos websites das prefeituras dos municípios de acordo com as determinações da Lei 12.527/11. Para cálculo do índice, foi elaborado o constructo a partir da referida Lei. O Quadro 1 apresenta as informações analisadas neste estudo. 
Quadro 1 - Informações a serem divulgadas.

\begin{tabular}{|l|}
\hline Itens \\
\hline 1. Legalidade \\
\hline 1.1 Indicativo de Lei de criação ao Acesso de Informação \\
\hline 2. Acessibilidade \\
\hline 2.1 Possui Link Direcionador para Acesso a Informação \\
\hline 2.2 Informado onde e como poderá ser obtidas informações (endereços, telefones, horários) \\
\hline 2.3 Apresenta formulário eletrônico para solicitação de informações \\
\hline 2.4 Possui Ouvidoria e indicativo de resposta \\
\hline 2.5 Possibilidade de download de arquivos e documentos \\
\hline 2.6 Possui mapa do site \\
\hline 3. Informações \\
\hline 3.1Indicativo do Responsável pelas Informações \\
\hline 3.2Informações sobre repasses e transferências financeiras a entidades \\
\hline 3.3 Processos licitatórios, contratos e informações patrimoniais \\
\hline 3.4 Divulgação de respostas às perguntas mais frequentes \\
\hline 3.5 As informações são apresentadas tempestivamente \\
\hline 3.6 Resultado de Auditoria, prestações de contas, Tomada de Contas Especiais \\
\hline 3.7 Informações de acompanhamento das ações públicas (obras, projetos, ações) \\
\hline 3.8 Registro de Despesas \\
\hline
\end{tabular}

Fonte: Lei $12.527 / 11$

Os dados foram obtidos nos websites oficiais dos municípios catarinenses entre os meses de outubro e dezembro de 2013. Na formação do índice, para cada informação, foi atribuída nota 0 (zero) ou 1 (um), sendo 1 para as informações que foram divulgadas e 0 para aquelas que não foram. Todas as questões receberam o mesmo peso e ao final cada município obteve uma pontuação que variou de 0 (representando $0 \%$ de evidenciação) a 15 (representando $100 \%$ de evidenciação). As análises dos índices de evidenciação foram realizadas utilizando-se de estatística descritiva (médias, mínimos, máximos e desvio padrão).

De forma complementar, foram verificadas quais informações apresentaram maior variabilidade de respostas, ou seja, quais informações, dentre as 15 analisadas, não estavam sendo divulgadas e quais foram as mais divulgadas. Para isso, usou-se a técnica de análise de entropia.

A fórmula do cálculo da entropia, segundo Zeleny (1982), pode ser apresentada seguindo alguns passos predefinidos:

Sejam $d_{i}=\left(d_{i}^{1}, d_{i}^{2}, \ldots, d_{i}^{m}\right)$ os valores normalizados, em que: $d_{i}^{k}=\frac{x_{i}^{k}}{x_{i}^{*}}$, caracteriza o conjunto $\mathrm{D}$, em termos do i-ésimo atributo. 
Encontra-se $\mathrm{D}_{\mathrm{i}}=\sum_{\mathrm{k}=1}^{\mathrm{m}} \mathrm{d}_{\mathrm{i}}^{\mathrm{k}} ; \mathrm{i}=1,2, \ldots, \mathrm{n}$. Busca-se então a medida de entropia do contraste de intensidade para o i-ésimo atributo calculado por $e\left(d_{i}\right)=-\alpha \sum_{k=1}^{m} \frac{d_{i}^{k}}{D_{i}} \operatorname{Ln}\left(\frac{d_{i}^{k}}{D_{i}}\right)$, em que $\alpha=\frac{1}{\mathrm{e}_{\max }}>0$ e $\mathrm{e}_{\max }=\mathrm{Ln}(\mathrm{m})$. Observa-se ainda que $0 \leq \mathrm{d}_{\mathrm{i}}^{\mathrm{k}} \leq 1$ e $\mathrm{d}_{\mathrm{i}}^{\mathrm{k}} \geq 0$.

Caso todos os $d_{i}^{k}$ forem iguais para um dado $i$, então $\frac{d_{i}^{k}}{D_{i}}=\frac{1}{n}$ e e $\left(d_{i}\right)$ assume o valor máximo, isto é, $e_{\max }=\operatorname{Ln}(m)$. Ao se fixar $\alpha=\frac{1}{e_{\max }}$, determina-se $0 \leq \mathrm{e}\left(\mathrm{d}_{\mathrm{i}}\right) \leq 1$ para todos os $\mathrm{d}_{\mathrm{i}}$ 's. Essa normalização é necessária para efeito comparativo.

Dessa maneira, a entropia total de D é definida por: $E=\sum_{i=1}^{n} e\left(d_{i}\right)$.

Quanto maior for $\mathrm{e}\left(\mathrm{d}_{\mathrm{i}}\right)$ menor é a informação transmitida pelo i-ésimo atributo. Caso $\mathrm{e}\left(\mathrm{d}_{\mathrm{i}}\right)=\mathrm{e}_{\mathrm{max}}=\mathrm{Ln}(\mathrm{m})$, então o i-ésimo atributo não transmite informação e pode ser removida da análise decisória. Em virtude do peso $\tilde{\lambda}_{\mathrm{i}}$ ser inversamente relacionado a e $\left(\mathrm{d}_{\mathrm{i}}\right)$, usa-se 1-e $\left(\mathrm{d}_{\mathrm{i}}\right)$ ao invés de e $\left(\mathrm{d}_{\mathrm{i}}\right)$ e normaliza-se para assegurar que $0 \leq \tilde{\lambda}_{\mathrm{i}} \leq 1$ e $\sum_{\mathrm{i}=1}^{\mathrm{n}} \tilde{\lambda}_{\mathrm{i}}=1$.

Assim, a entropia da informação pode ser representada por:

$$
\tilde{\lambda}_{\mathrm{i}}=\frac{1}{\mathrm{n}-\mathrm{E}}\left[1-\mathrm{e}\left(\mathrm{d}_{\mathrm{i}}\right)\right]=\frac{\left[1-\mathrm{e}\left(\mathrm{d}_{\mathrm{i}}\right)\right]}{\mathrm{n}-\mathrm{E}} \text {. }
$$

Na sequência, foi calculada a eficiência na utilização das receitas pelos municípios catarinenses referentes ao ano de 2012. Para calcular a eficiência, adotou-se a mesma metodologia de Beuren, Moura e Kloeppel (2013) que verificaram a combinação das receitas correntes e de capital com o Índice de Desenvolvimento Humano Municipal (IDHM), Produto Interno Bruto (PIB) e tamanho. O IDHM foi medido pelo indicador total do IDH municipal, obtido no site do Programa das Nações Unidas para o Desenvolvimento (PNU) e refere-se ao ano de 2010. O PIB foi mensurado pelo valor do produto interno bruto per capita de cada município, obtido no site do Instituto Brasileiro de Geografia e Estatística (IBGE) e refere-se ao ano de 2010. O tamanho foi medido pela população de cada município, com dados obtidos no site do IBGE e refere-se também ao ano de 2010. A utilização dos índices, nesses respectivos anos, deu-se por serem os resultados mais recentes divulgados para a amostra no momento da realização da pesquisa.

Para o cálculo da eficiência foi utilizado o software estatístico MaxDEA, cujo modelo matemático do DEA (Análise Envoltória de Dados), de acordo com Kassai (2002), foi proposto, inicialmente, por Charnes, Cooper e Rhodes, em 1978. Segundo Charnes et al. (1994), possui dois modelos básicos geralmente usados nas aplicações. O primeiro é o CCR (CHARNES; COOPER; RHODES, 1978), também conhecido como CRS (Constant Returns to Scale), avalia a eficiência total, identifica as Unidades de Análises - DMU's eficientes e ineficientes e determina a que distância da fronteira de eficiência está as unidades ineficientes. O segundo, adotado nesta pesquisa, é o modelo BCC (BANKER; CHARNES; COOPER, 1984), também conhecido como VRS (Variable Returns to Scale), utiliza uma formulação que permite a projeção de cada DMU ineficiente sobre a superfície de fronteira (envoltória) determinada pelas DMU's eficientes de tamanho compatível. 
O cálculo, segundo Zhu (2000), mostra o quanto uma instituição é eficiente, no tratamento de seus inputs e outputs, em relação às outras, numa análise que fornece um indicador que varia de 0 a 1 . Somente as instituições que obtêm índice de eficiência igual a 1 é que fazem parte da fronteira eficiente.

Nesta pesquisa, avaliaram-se as melhores combinações de receitas relacionadas com IDH, PIB e tamanho. No Quadro 2, apresenta-se a formação das Unidades de Análise - DMU.

Quadro 2 - Definição das unidades de análise ou conceito de eficiência.

\begin{tabular}{|c|c|c|c|c|c|}
\hline DMU & Input 1 & Input 2 & Output 1 & Output 2 & Output 3 \\
\hline Municípios & Rec. Correntes & Rec. de Capital & PIB & IDHM & Tamanho \\
\hline
\end{tabular}

Neste estudo, assim como na pesquisa de Beuren, Moura e Kloeppel (2013), primeiro foram avaliadas as combinações entre as receitas públicas utilizadas e os indicadores socioeconômico e tamanho. Após encontrar os indicadores de eficiência, estes foram relacionados com os índices de evidenciação. De acordo com Beuren, Moura e Kloeppel (2013), essa maneira é mais adequada, haja vista que possibilita verificar quais Estados são mais eficientes ao considerar todas as variáveis. Avaliar os indicadores de maneira isolada, segundo os autores, não considerando qual Estado é mais eficiente no conjunto, poderia prejudicar a análise. Para analisar os indicadores de eficiência também foram utilizadas medidas de estatística descritiva (médias, mínimos, máximos e desvio padrão).

Por fim, utilizou-se ainda na análise estatística o teste de Kolmogorov-Smirnov, a fim de testar se a distribuição amostral possuía normalidade dos dados. O resultado do teste foi positivo, portanto, optou-se por utilizar o coeficiente de correlação de Pearson para verificar a correlação existente entre os índices de evidenciação e de eficiência.

\section{DESCRIÇÃO E ANÁLISE DOS DADOS}

Esta seção contém a descrição e análise dos dados coletados. Primeiramente, apresentam-se as estatísticas descritivas do índice de evidenciação dos municípios de Santa Catarina, elaborado com base na Lei 12.527/11. Em seguida, os resultados do cálculo da entropia da informação que permitiu identificar quais informações não estavam sendo evidenciadas pelos municípios da amostra. Após, expõem-se as estatísticas descritivas do cálculo da eficiência da combinação de receitas correntes e receitas de capital relacionadas com IDH, PIB e tamanho. E, por último, demonstram-se os resultados da correlação de Pearson, que possibilitou alcançar o objetivo da pesquisa.

Na Tabela 1, são apresentados os resultados da avaliação do índice de evidenciação elaborado com base na Lei 12.527/11. 
Tabela 1 - Estatística descritiva dos índices de evidenciação dos municípios de Santa Catarina.

\begin{tabular}{l|c|c|c|c|c}
\hline Municípios de S.C. & $\begin{array}{c}\boldsymbol{N}^{\boldsymbol{o}} \\
\text { Municipios }\end{array}$ & $\begin{array}{c}\text { Mínimo } \\
\mathbf{\%}\end{array}$ & $\begin{array}{c}\text { Máximo } \\
\mathbf{\%}\end{array}$ & $\begin{array}{c}\text { Média } \\
\mathbf{\%}\end{array}$ & $\begin{array}{c}\text { Desvio Pad. } \\
\mathbf{\%}\end{array}$ \\
\hline Acima de 100.001 & 12 & 21,43 & 95,71 & 60,60 & 22,03 \\
Entre 75.001 e 100.000 & 3 & 7,14 & 92,86 & 53,81 & 43,37 \\
Entre 50.001 e 75.000 & 10 & - & 85,71 & 43,57 & 34,25 \\
Entre 25.001 e 50.000 & 21 & - & 85,71 & 41,16 & 32,41 \\
Entre 20.000 e 25.000 & 15 & - & 92,86 & 43,81 & 37,98 \\
\hline Totais & $\mathbf{6 1}$ & - & $\mathbf{9 5 , 7 1}$ & $\mathbf{4 6 , 6 5}$ & $\mathbf{3 2 , 7 1}$ \\
\hline
\end{tabular}

Fonte: Dados da Pesquisa.

Nota-se, na Tabela 1, que a melhor média $(60,60 \%)$ de evidenciação das informações, refere-se ao grupo de municípios com população superior a 100.000,00 habitantes. O índice mínimo desse grupo foi de $21,43 \%$ e o máximo foi de $95,71 \%$. O desvio padrão desse grupo $(22,03 \%)$ foi o menor, no entanto, demonstra que existem diferenças significativas entre os índices de evidenciação.

O grupo de municípios com população entre 75.000,01 e 100.00 habitantes também se destacaram, pois, em média, possuíam $53,81 \%$ das informações evidenciadas, dentre os 15 itens analisados. O índice mínimo desse grupo foi de 7,14\% e o máximo $92,86 \%$. O desvio padrão demonstra que existem grandes desigualdades nos índices de evidenciação nesse grupo.

Percebe-se ainda, pela Tabela 1, que o grupo de municípios com população entre $25.000,01$ e 50.000 habitantes possuía a menor média, com apenas $41,16 \%$ de informações evidenciadas, que são obrigatórias, de acordo com a Lei 12.527/11. O índice máximo nesse grupo foi de $85,71 \%$. Cabe destacar ainda que, nesse grupo, existiam municípios em que nenhuma das informações obrigatórias foi divulgada nas respectivas páginas da internet.

De forma geral, têm-se um índice médio de evidenciação de apenas $46,65 \%$, muito distante de $100 \%$. Alguns municípios não divulgaram nenhuma das informações, dentre as 15 analisadas. O índice máximo atingindo foi de 95,71\%. Ressalta-se também o fato de que nenhum município catarinense atingiu $100 \%$ de informações obrigatórias divulgadas.

A Tabela 2 evidencia os resultados da entropia informacional dos quinze itens analisados e que formam o índice de evidenciação obrigatória, elaborado com base na Lei $12.527 / 11$. 
Tabela 2 - Entropia informacional da dimensão da evidenciação.

\begin{tabular}{|c|c|c|c|}
\hline $\mathbf{N}^{\mathbf{o}}$ & Questões & $\begin{array}{l}\text { Entropia } \\
\qquad \mathbf{e}\left(\mathbf{d}_{\mathbf{i}}\right)\end{array}$ & $\begin{array}{c}\text { Peso da } \\
\text { questão } \tilde{\lambda}_{i}\end{array}$ \\
\hline 1 & Indicativo da Lei de criação ao Acesso de Informação & 0,9859 & 0,0531 \\
\hline 2 & Possui Linck Direcionador para Acesso a Informação & 0,9866 & 0,0509 \\
\hline 3 & $\begin{array}{l}\text { Informado onde e como poderá ser obtidas informações (endereços, } \\
\text { telefones, horários) }\end{array}$ & 0,9871 & 0,0489 \\
\hline 4 & Apresenta formulário eletrônico para solicitação de informações & 0,9922 & 0,0295 \\
\hline 5 & Possui Ouvidoria e indicativo de resposta & 0,9880 & 0,0454 \\
\hline 6 & Possibilidade de download de arquivos e documentos & 0,9937 & 0,0237 \\
\hline 7 & Possui mapa do site & 0,9658 & 0,1292 \\
\hline 8 & Indicativo do Responsável pelas Informações & 0,9771 & 0,0867 \\
\hline 9 & Informações sobre repasses e transferências financeiras & 0,9887 & 0,0427 \\
\hline 10 & Processos licitatórios, contratos e informações patrimoniais & 0,9922 & 0,0295 \\
\hline 11 & Divulgação de respostas às perguntas mais frequentes & 0,9877 & 0,0466 \\
\hline 12 & As informações são apresentadas no prazo - tempestivamente & 0,9917 & 0,0313 \\
\hline 13 & $\begin{array}{l}\text { Resultado de Auditoria, prestações de contas, Tomada de Contas } \\
\text { Especiais }\end{array}$ & 0,9764 & 0,0894 \\
\hline 14 & $\begin{array}{l}\text { Informações de acompanhamento das ações públicas (obras, projetos, } \\
\text { ações) }\end{array}$ & 0,9622 & 0,1429 \\
\hline 15 & Registro de Despesas & 0,9603 & 0,1502 \\
\hline \multicolumn{2}{|c|}{ Totais } & 14,7356 & 1,0000 \\
\hline
\end{tabular}

Fonte: dados da pesquisa.

Em relação às 15 informações do índice de evidenciação, percebe-se, na Tabela 2, que os maiores $\mathrm{e}\left(\mathrm{d}_{\mathbf{i}}\right)=0,9937,0,9922,0,9922$ e 0,9917 encontram-se nas informações de $\mathrm{n}^{\mathbf{o}} 6$ sobre "possibilidade de download de arquivos e documentos", de $\mathrm{n}^{\mathrm{o}} 4$ "apresenta formulário eletrônico para solicitação de informações", $\mathrm{n}^{\circ} 10$ "processos licitatórios, contratos e informações patrimoniais" e $\mathrm{n}^{\circ} 12$ "as informações são apresentadas no prazo tempestividade", ou seja, essas questões apresentam a menor informação transmitida. Segundo Zeleny (1982), quanto maior for o e $\left(\mathrm{d}_{\mathbf{i}}\right)$, menor é a informação transmitida, nesse caso, menor é a variação nas respostas, significando que essas informações obrigatórias são as mais evidenciadas pelos municípios catarinenses.

Analisando o peso $\left(\tilde{\lambda}_{i}\right)$ de cada questão calculado em relação ao total do grupo (15 questões), observa-se que as questões que apresentaram maiores pesos $\left(\tilde{\lambda}_{i}\right)=0,1502,0,1429$ e 0,1292 foram, respectivamente, as questões $n^{\circ} 15$ "registro de despesas", $n^{\circ} 14$ "informações de acompanhamento das ações públicas (obras, projetos, ações)" e a questão de $n^{0} 7$ "possui mapa no site". No caso destas informações, ocorreram maiores variações nas respostas obtidas, significando que um número maior de municípios não cumpriu com estas obrigatoriedades. Sendo assim, essas informações são as informações menos divulgadas pelos municípios catarinenses. 
Caso alguma informação tivesse sido evidenciada por todos os municípios, atingiria a máxima entropia $\mathrm{e}\left(\mathrm{d}_{\mathrm{i}}\right)=1$. Nesse caso, de acordo com Zeleny (1982), não haveria a transmissão de nenhuma informação no grupo. Porém, nesse estudo, nenhuma das informações obrigatórias analisadas foi divulgada por todos os municípios da amostra.

De forma geral, a maioria dos $\mathrm{e}\left(\mathrm{d}_{\mathrm{i}}\right)$ ficaram com valores entre 0,9771 e 0,9887 indicando que existe uma quantidade considerável de municípios que não cumpriram a Lei 12.527/11, pois não divulgaram informações obrigatórias. Então, essas informações também merecem atenção, haja vista que, prejudicam o nível de transparência por não estarem disponíveis.

Tabela 3 - Estatística descritiva do cálculo da eficiência na utilização dos recursos públicos pelos municípios.

\begin{tabular}{l|c|c|c|c|c}
\hline Municípios de S.C. & $\begin{array}{c}\boldsymbol{N}^{\boldsymbol{o}} \\
\text { Municípios }\end{array}$ & $\begin{array}{c}\text { Mínimo } \\
\boldsymbol{\%}\end{array}$ & $\begin{array}{c}\text { Máximo } \\
\boldsymbol{\%}\end{array}$ & $\begin{array}{c}\text { Média } \\
\boldsymbol{\%}\end{array}$ & $\begin{array}{c}\text { Desvio Pad. } \\
\%\end{array}$ \\
\hline Acima de 100.001 & 12 & 0,9562 & 1,0000 & 0,9833 & 0,0190 \\
Entre 75.001 e 100.000 & 3 & 0,9453 & 1,0000 & 0,9818 & 0,0316 \\
Entre 50.001 e 75.000 & 10 & 0,8485 & 1,0000 & 0,9510 & 0,0485 \\
Entre 25.001 e 50.000 & 21 & 0,9075 & 1,0000 & 0,9630 & 0,0333 \\
Entre 20.000 e 25.000 & 15 & 0,8940 & 1,0000 & 0,9694 & 0,0314 \\
\hline Totais & $\mathbf{6 1}$ & $\mathbf{0 , 8 4 8 5}$ & $\mathbf{1 , 0 0 0 0}$ & $\mathbf{0 , 9 6 7 5}$ & $\mathbf{0 , 0 3 4 2}$ \\
\hline
\end{tabular}

Fonte: dados da pesquisa.

É importante ressaltar que, na Tabela 3, os municípios que obtiveram score 1 são os mais eficientes da amostra, ou seja, são aqueles que possuem melhores combinações de receitas correntes e receitas de capital com IDH, PIB e tamanho.

O grupo de municípios que possuem população acima de 100.000 habitantes apresentou a maior média (0,9833), sendo que 6 municípios atingiram score 1 e podem ser considerados mais eficientes. Os estados eficientes desse grupo foram: Joinville, Florianópolis, São José, Itajaí, Palhoça e Balneário Camboriú. O município com o menor score $(0,9562)$ foi o município de Lages. O baixo desvio padrão $(0,0190)$ demonstra homogeneidade na eficiência entre os municípios de grupo.

Os municípios com população entre 75.000,01 e 100.000 habitantes atingiram score médio $(0,9818)$ muito próximo ao do primeiro grupo, e, entre os três municípios, apenas um não obteve score 1 e foi considerado menos eficiente. Trata-se do município de São Bento do Sul. Tubarão e Caçador são os municípios que atingiram score 1 e podem ser considerados mais eficientes na utilização dos recursos públicos.

Os municípios com população entre 50.000,01 e 75.000 habitantes obtiveram o menor score médio equivalente a 0,9510 . Neste grupo, apenas 3 municípios alcançaram score 1 , são eles: Concórdia, Araranguá e Mafra. Cabe destacar ainda que o município com menor score (Rio do Sul), entre os 61 analisados, faz parte desse grupo e obteve score de 0,8485 . O desvio padrão de $(0,0485)$ foi o mais elevado entre os cinco grupos, evidenciando que existiam diferenças significativas na eficiência dos municípios desse grupo.

De forma geral, os cálculos obtidos por meio do DEA demonstraram que, dos 61 municípios, 22 deles atingiram score 1, ou seja, as minorias dos municípios catarinenses revelaram-se eficientes na utilização dos recursos públicos. 
Na Tabela 4 evidenciam-se os coeficientes de correlação de Pearson, a fim de verificar se há correlação entre evidenciação obrigatória e eficiência na utilização dos recursos públicos.

Tabela 4 - Correlação das variáveis.

\begin{tabular}{lcc}
\hline ÍNDICES & Evidenciação obrigatória & Eficiência \\
\hline Evidenciação obrigatória & 1 & \\
Eficiência & 0,165 & 1 \\
\hline
\end{tabular}

Fonte: dados da pesquisa.

Verifica-se, na Tabela 4, que a variável evidenciação obrigatória tem correlação positiva de $16 \%$ com a variável eficiência na utilização das receitas públicas, no entanto, não estatisticamente significativa a um nível de significância de 0,10 . Portanto, os resultados indicam que não é possível afirmar que os municípios catarinenses com melhores níveis de evidenciação foram os que apresentaram maior eficiência na utilização dos recursos públicos, ou seja, melhor combinação de receitas correntes e receitas de capital com IDH, PIB e tamanho.

\section{CONSIDERAÇÕES FINAIS}

A pesquisa objetivou analisar o nível de transparência dos municípios do Estado de Santa Catarina sob a ótica da Lei 12.527/2011 e sua correlação com a eficiência na utilização das receitas. Para tal, realizou-se pesquisa descritiva, conduzida por meio de análise documental e abordagem quantitativa. A amostra, intencional e não probabilística, compreendeu 61 municípios catarinenses. $\mathrm{Na}$ análise dos dados utilizaram-se medidas de estatísticas descritivas, entropia informacional, cálculo da eficiência com o software MaxDEA e análise de correlação de Pearson.

Os resultados revelaram um nível médio de evidenciação de apenas 46,65\%, muito distante de $100 \%$. Alguns municípios não divulgaram nenhuma das informações e nenhum deles atingiu $100 \%$ de informações evidenciadas. A melhor média $(60,60 \%)$ de evidenciação das informações, refere-se ao grupo de municípios com população superior a $100.000,00$ habitantes. O grupo de municípios com população entre 25.000,01 e 50.000 habitantes possuía a menor média, com apenas $41,16 \%$ de informações obrigatórias evidenciadas.

Os resultados da entropia informacional evidenciaram que as informações de $\mathrm{n}^{\circ} 6$ sobre "possibilidade de download de arquivos e documentos", de $n^{\circ} 4$ "apresenta formulário eletrônico para solicitação de informações", $\mathrm{n}^{\mathrm{o}} 10$ "processos licitatórios, contratos e informações patrimoniais" e $\mathrm{n}^{\mathrm{o}} 12$ "as informações são apresentadas no prazo tempestividade" são as informações obrigatórias mais evidenciadas pelos municípios catarinenses. De modo contrário, as informações de $\mathrm{n}^{\mathrm{o}} 15$ "registro de despesas", $\mathrm{n}^{\mathrm{o}} 14$ "informações de acompanhamento das ações públicas (obras, projetos, ações)" e a questão de no 7 "possui mapa no site", eram as informações menos divulgadas pelos municípios catarinenses.

Os cálculos obtidos por meio do DEA demonstraram que 22 munícipios, dos 61 analisados, atingiram score 1 , ou seja, apenas a minoria pôde ser considerada eficiente na utilização dos recursos públicos. O grupo de municípios que possuíam população acima de 100.000 habitantes apresentou a maior média $(0,9833)$, sendo que 6 municípios atingiram score 1 e podem ser considerados mais eficientes. Os municípios eficientes desse grupo

GєCont, v. 1, n. 2, Floriano-PI, Jul-Dez. 2014. 
foram: Joinville, Florianópolis, São José, Itajaí, Palhoça e Balneário Camboriú. Por outro lado, os municípios com população entre 50.000,01 e 75.000 habitantes obtiveram o menor score médio equivalente a 0,9510. Neste grupo, apenas 3 municípios alcançaram score 1 , são eles: Concórdia, Araranguá e Mafra.

Por fim, constatou-se que a variável evidenciação obrigatória apresentava correlação positiva de $16 \%$ com a variável eficiência na utilização das receitas públicas, no entanto, não era estatisticamente significativa. Sendo assim, os resultados sinalizam que a combinação entre receitas públicas utilizadas e os indicadores socioeconômico e tamanho não são variáveis que contribuem para aumentar o nível de evidenciação obrigatória.

Os resultados despertam interesses para novas pesquisas sobre o nível de transparência dos municípios e também sobre a eficiência na utilização das receitas. Recomenda-se, inicialmente, acompanhar os índices de evidenciação e eficiência nos municípios catarinenses. Também seria interessante realizar esta análise em municípios de outros estados e regiões brasileiras, a fim de comparar com os resultados obtidos nesta pesquisa.

\section{REFERÊNCIAS}

AKUTSU, L.; PINHO, J. A. G. Sociedade da informação, accountability e democracia delegativa: investigação em portais de governo no Brasil. Revista de Administração Pública, Rio de Janeiro, v. 36, n. 5, p.723-745, set./out. 2002.

AMORIM, S.N.D. Ética na esfera pública: a busca de novas relações Estado/Sociedade. Revista do Serviço Público. Brasília, Enap, ano 41, n. 2, p. 95-105, jun. 2000 .

BANKER, Rajiv D.; CHARNES, Abraham; COOPER, William W. Models for estimating technical and scale inefficiencies in data envelopment analysis. Management Science, v. 30, n. 9, p. 1078-1092, 1984.

BEUREN, I.M.; MOURA, G. Dias de; KLOEPPEL, N.R. Práticas de governança eletrônica e eficiência na utilização das receitas: uma análise nos estados brasileiros. Revista de Administração Pública, v. 47, n. 2, p. 421-441, mar./abr. 2013.

BELLVER, A.; KAUFMANN, D. Transparenting transparency: initial empirics and policy applications. The World Bank, 2005. Disponível em: <http://siteresources.worldbank.org/INTWBIGOVANTCOR/Resources/Transparenting_Tran sparency171005.pdf $>$. Acesso em 07 setembro de 2013.

BRASIL. Lei Complementar $n^{\circ}$ 101/2000, de 4 de maio de 2000. Estabelece normas de finanças públicas voltadas para a responsabilidade na gestão fiscal e dá outras providências. 2000.2 Disponível em: <http://www.planejamento.gov.br//rf/conteudo/integra_lei/lei_101_portugues.htm>. Acesso em: 03 setembro de 2013.

BRASIL. Constituição (1988). Constituição da República Federativa do Brasil: promulgada em 5 de outubro de 1988.

BRASIL. Decreto 7.185 de 27 de maio de 2010. Dispõe sobre o padrão mínimo de qualidade do sistema integrado de administração financeira e controle, no âmbito de cada ente da Federação, nos termos do art. 48, parágrafo único, inciso III, da Lei Complementar $\mathrm{n}^{\mathrm{o}}$ 101, de 4 de maio de 2000, e dá outras providências. Disponível em: 
<http://www.planalto.gov.br/ccivil_03/_ato2007-2010/2010/decreto/d7185.htm>. Acesso em 13 agosto 2014.

CAMPOS, A.M. Accountability: quando poderemos traduzi-la para o português? Revista de Administração Pública, v. 24, n. 2, p. 30-50, fev./abr. 1990.

CHARNES, A.et al. Data envelopment analysis. 2 ed. Boston: Kap, 1994.

CHARNES, A.; COOPER, W.W.; RHODES, E. Measuring the efficiency of decision making units. European Journal of Operational Research, v. 2, p. 429-444, 1978.

CRUZ, C.F.; SILVA, L.M.; SANTOS, R. Transparência da gestão fiscal: um estudo a partir dos portais eletrônicos dos maiores municípios do estado do Rio de Janeiro. Contabilidade, Gestão e Governança. Brasília. v. 12. n. 3. p. 102 - 115. set/dez 2009.

CRUZ, C.F.; FERREIRA, A.C.de Souza.; SILVA, L.M.; MACEDO, M. A. da Silva. Transparência da gestão fiscal: um estudo a partir dos portais eletrônicos dos maiores municípios brasileiro. Revista de Administração Pública. Rio de Janeiro. v.46 p. 153-76, jan./fev. 2012.

KASSAI, S. Utilização da Análise por Envoltória de Dados (DEA) na análise de demonstrações contábeis. Tese (doutorado em economia) — Universidade de São Paulo, São Paulo, 2002.

KEUNECKE, L.P; TELES, J; FLACH, L. Práticas de Accountability: uma análise do índice de transparência nos municípios mais populosos de Santa Catarina. Revista Contemporânea de Contabilidade. UFSC, Florianópolis, v.8, n.16, p. 153-174, jul./dez. 2011.

LEMOS, A.; MAMEDE, J.; NÓBREGA, R.; PEREIRA, S.; MEIRELLES, L. Cidade, tecnologia e interfaces. Análise de interfaces de portais governamentais brasileiros. Uma proposta metodológica. Revista Fronteira - estudos midiáticos. V. VI, n. 2. jul/dez. 2004.

MEIRELLES, H.L.. Direito administrativo brasileiro. 32a ed. São Paulo: Malheiros, 2006.

PLATT NETTO, O.A.P. CRUZ,F. da. ENSSLIN,S. R. ENSSLIN, L. Publicidade e Transparência das Contas Públicas: obrigatoriedade e abrangência desses princípios na administração pública brasileira. Contabilidade Vista \& Revista. Belo Horizonte. v. 18, n. 1, p. 75-94, jan./ mar. 2007.

PRADO, O. Governo eletrônico e transparência: a publicização das contas públicas das capitais brasileiras. 2004. 180 p. Dissertação (Mestrado em Administração Pública e Governo) - Escola de Administração de Empresas de São Paulo da Fundação Getulio Vargas, São Paulo, 2004.

RAUPP, F. M; PINHO, J. A.G.de. Prestação De Contas, Transparência e Participação em Portais Eletrônicos de Câmaras Municipais. Cadernos da Escola do Legislativo. Minas Gerais. v.14, n. 22, p. 47-73, jul./dez. 2012.

VICCARI JUNIOR, A.; CRUZ, F. da; GLOCK, J. O; HERZMANN, Nélio; TREMEL, Rosângela. Lei de Responsabilidade Fiscal Comentada: lei complementar $n^{\circ}$ 101, de 4 de maio de 2000. Editora Atlas: São Paulo, 2009.

ZELENY, M. Multiple criteria decision making. New York: McGraw-Hill, 1982.

ZHU, Joe. Multi-factor performance measure model with application to fortune 500 companies. European Journal of Operational Research, v. 123, n. 1, p. 105-124, 2000. 